\title{
Challenging Job Demands and Performance: The Role of Learning Orientation
}

\author{
Irene Hau-Siu Chow \\ Hang Seng University of Hong Kong \\ Yuanyuan Gong \\ Okayama University
}

Drawing on the job demand-control and job demand-resource models, this study examines the curvilinear relation between challenge job demand and performance outcomes (task and creative performance) as well as the moderating effect of employee learning orientation on such relationships. Data were obtained from 216 employees and 47 supervisors of service firms in China. Results showed that employee learning orientation moderates the inverted U-shaped relation between challenge job demand and task performance and creativity, such that the curvilinear effect is stronger for employees with high learning orientation, but no effect was observed with low learning orientation. Theoretical and practical implications are provided.

\section{INTRODUCTION}

How and under what condition does job demand affect work outcomes such as creativity and performance? Much past research has recognized that some job-related demands are conducive to positive work outcomes (Podsakoff, LePine, \& LePine, 2007), yet others can be destructive to individual wellbeing and performance (Kelly \& Karau, 1999; Lazarus, 1991), resulting in burnout (Schaufeli \& Taris, 2005). Cavanough, Boswell, Rochling, and Boudreau (2000) describes the characteristics of jobs in making a distinction between job demands that can be either challenging or hindering. While hindrance job demands lead to excessive and undesirable outcome (health - impairment process) and challenging job demands beneficial. Challenging job demands, also known as challenge stressors, are factors that potentially promote employees' personal growth and achievement (Podsakoff et al., 2007), such as high workloads, time pressure, and responsibility, which can yield rewarding work experiences and higher performance. Although challenging job demands could enhance task and creative performance, there may be negative consequences of this positive type of stress irrespective of its potential gains (Scheck, Kinicki \& Davy, 1995). Individuals may feel exhausted under excessive job demands while too few may be perceived as insufficient, hence we suggest a curvilinear relationship. Most people might perceived job demand as ranging between low to high, with the optimal occurring at the intermediate level.

As work becomes more dynamic and decentralized, employee reaction to job demands serves as a vital determinant of competitive workforce. This study focuses on challenging job demands as it is believed to be associated with employee performance outcomes, such as job satisfaction and commitment, 
intention to leave, job search, and task performance (Boswell, Olson-Buchanan, \& LePine, 2004; Cavanaugh et al., 2000; LePine, Podsakoff, \& LePine, 2005). Yet these results show both positive and negative relationships, as well as curvilinear ones between specific challenging stressors and certain performance outcomes (Boswell et al., 2004; Byron et al., 2010; Cavanaugh et al., 2000). Since results linking challenge job demands to performance have been inconclusive (Byron, Khazanchi, \& Nazarian, 2010), it warrants a deeper theorization and investigation. More research is needed to examine the relationships between overall challenging job demands and different types of performance with clear empirical evidence and the theoretical framework.

The job demand-control model (Karasek, 1979) provides an important research framework for an individual's coping mechanism under these conditions. Job demands increase time pressure and stress, while job control shows an individual's better sense of control over his or her tasks in various situations. Individuals respond differently to job demands. People vary in their perceptions of and reactions to stressors. Individuals with better control over their job demand can better cope with burden of workload and stress. Job demand-resource (JD-R) model states that the burden of job demand can be alleviated by job resources (Bakker \& Demerouti, 2007). Job resources serve to restore energy, to mitigate negative effects of job demands. Various job resources such as autonomy and opportunity for professional development buffer the impact of job demand on strain. Learning and knowledge represents a kind of job resources that helps employees maintain certain level of motivation that facilitates job performance. Learning goal orientation is commonly defined as the desire to learn and develop new competence, to improve and to do one's best, and to achieve a higher level of ability and talent (Dweck, 1986). Individual differences in learning goal orientation may help to determine if employees can effectively tackle with challenging job demands (Gong, Huang, \& Farh, 2009). The extent to which employees show concern for, and dedicate themselves to developing competences helps determine if they can successfully translate job demand into performance (Dweck, 2007). Individuals high in learning orientation may be more willing to try out their ideas, and show less withdraws in face of difficulty (Gong et al., 2009). Thus, the effect of challenge job demands on performance depends on individual's learning orientation. By integrating job demand-control and job demand-resource models, this study attempts to examine the moderating role of learning goal orientation in the relationship between challenging job demands and employee job performance.

Taken together, the objectives of the study are two-fold. Given the inconsistent results of challenging job demands on employee work outcomes, it aims to explore the curvilinear effect of challenging job demands on task performance (traditional job performance) and creative performance (challenging statusquo performance). Creative performance is defined as "production, conceptualization, or development of novel and useful ideas, processes, or procedures" (Shalley, Gilson, \& Blum, 2000: p. 215). In addition, it examines the moderating role of employee learning orientation with respect to the curvilinear effect of job demand challenge. Thus, this study contributes to the literature in three ways. First, it responds to the Byron et al.'s (2010) call for a better understanding of mechanism through which challenging job demands influence job performance. Specifically, this study contributes to the current literature by untwining the inconsistent relationships between challenging job demands and performance. This study posits a curvilinear relationship to disentangle the mix findings. Second, it adds to current job demands literature through simultaneously delving into two types of job performance (task and creative performance). Further, it looks into the moderating effect of learning goal orientation to see how the existing relationships are influenced by coping-related personal resource in the study. Finally, this study is one of the first to use a large sample of supervisors and their employees in China to test the effects of challenging jobs and their effects, particularly on creative and innovative performance. This is particularly important as researchers and practitioners both struggle with how to improve the ability to innovate and proactively prompt change. 


\section{THEORY AND HYPOTHESES}

\section{Challenging Job Demands that Hamper Job Performance}

The stress job demand model or the health-impairment process highlights the negative consequences of job demand. Job demand leads to heavy workload and stress, through exhaustion resulting in poor performance outcomes. When job demands grow beyond one's capacity to cope, they trigger negative emotion and cognition, which ultimately translates into coping in the form of emotional and physical withdrawal from work. Job demands exceeding an individual's resources and capability creates physical and psychological stress. Rodell and Judge (2009) suggest that challenging job demands include a certain level of uncertainty, representing a potential threat. Risks often exist that deadlines be missed or job scope extends beyond one's capacity. Perrewe and Ganster (1989) find that excessive work pressure exceeding the individual's capacity results in frustration, tension, stress and dissatisfaction with work. Basically, overly challenging job demands such as time pressure and workload could increase strain, emotional exhaustion, anxiety, and depression (Boswell et al., 2004; LePine et al., 2005).

The stress job demands model states that job demands evoke strain that requiring sustained effort on the part of employee. Thus job demands can result in poor performance, disengagement, absenteeism and turnover. Job demands exhaust employees' resource and drain their energy. Emotional and cognitive effort involved in coping processes results in fatigue and exhaustion (Cooper, Dewe, \& O'Driscoll, 2001), which in turn detracts from performance. Thus a high level of job demands tends to reduce task and creative performance. Employees seek to obtain, retain, and protect valued resources in tackling with challenging job demands (Hobfoll, 1989). When they perceive a demand as potentially threatening or eventually harmful, they will feel anxiousness and discomfort, using up energy and time to cope with these stressors (Roth \& Cohen, 1986). Therefore, excessive challenging job demands adversely affect an individual's performance outcomes by diverting effort away from regular job duties toward coping with the stressors.

\section{Challenging Job Demands, Job Control, and Job Performance}

The job demands-job performance relationship is not necessarily negative. A number of studies have revealed the positive effects of challenging job demands on work task performance (Cavanaugh et al., 2000; LePine et al., 2005). For example, extant evidence shows that role overload is positively associated with performance (Gilboa, Shirom, Fried, \& Cooper, 2008). When a stressor is viewed as challenging, it enhances intrinsic motivation and higher performance outcomes (LePine et al., 2005). It follows that challenging job demands promote task and creative performance through the similar mechanism.

The job demand-control model (Karasek, 1979) provides a useful framework for explaining the relationship between challenge job demand and job performance. The model includes two elements, i.e., job demand and job control. Job demand is defined as work load, operationalized mainly in terms of time pressure and role conflict. Job control, or job decision latitude, refers to an individual's potential control over his tasks. According to this model, job demand alone could easily cast a negative impact on individual well-being, but individual ability to exercise control of the task intervenes to buffer against the negative impact and lead to improved psychological wellbeing as well as work outcomes (Van Der Doef \& Maes, 1999). According to job demand-control model, the intrinsic motivation from demanding jobs works best with job control. Individuals with better control over their job demands can better cope with burden of workload and stress (Häusser et al., 2010).

The characteristics of job demands as reflected by high levels of workload, time pressure, job scope, and responsibility are directly related to individual motivation to perform (Van der Doef \& Maes, 1999). Challenging and intellectually stimulating job demand exerts its influence on task and creative performance (Zhou \& Shalley, 2003). Study by Amabile and Gryskiewicz (1989) demonstrated a significant relationship between challenging work and creativity. Rodell and Judge (2009) further maintain that the characteristics of challenging job demands tend to produce a positive motivational effect, over and beyond the stressful feelings caused by the stressors. Because individuals tend to appraise 
challenging job demands as opportunities for growth, learning, and goal attainment, they generally strive to achieve the opportunities available in challenge stressors such as learning and goal attainment.

Challenging job demands tend to generate positive emotions, which could be further translated to performance outcomes (Rodell \& Judge, 2009). Research on managerial job demands and development (McCauley \& McCall, 2014) further suggest that even a pressure-laden, anxiety producing experience can be viewed as rewarding and worth the discomfort involved, and can result in enhanced attitudes due to a feeling of net gain. Lazarus (1991) also argued that positive emotions are reactions to incidents that show achievement and progress toward a favorable outcome. For example, workload is positively related to job satisfaction (Dwyer \& Ganster, 1991). In addition, successfully handling job stressors generates positive emotions such as self-worth (Lazarus, 1991) and attainableness (Rodell \& Judge, 2009). Individuals in better sense of control over various situations will get more involved with the tasks at hand and coming up with more novel ideas. For example, Staw and colleagues (1993) found that affective events are related to task quality, productivity, and efficiency. Positive affect also leads to greater cognitive flexibility and facilitates creative problem solving across a broad range of settings (Fredrickson, 2001). Therefore, the challenging aspect of job demand could be positively related to task performance and creative output.

In summary, although challenging job demands link to positive outcomes, there is evidence of increased strain at high levels of job scope, complexity, leading to negative outcomes. Individuals' perception of job demands can be either positive or negative. Too much or excessive demands will have unfavorable effect on performance outcomes and interfere with individual well-being. In view of the inconsistent and conflicting outcome a curvilinear inverted U-shaped relationship is proposed. Individuals will be most creative at moderate levels of activation (Gardner, 1990). Moderate activation levels increase task involvement, which leads to the optimal use of available resources (Baer \& Oldham, 2006). Too little or too much stressors can lead to a lack of engagement and cause cognitive interference, which eventually hinder performance on cognitively demanding tasks. Hence, challenging job demands could be curvilinearly related to task and creative performance.

Janssen (2001) investigated the curvilinear relationship between job demands and innovative job performance. An inverted U-shaped relationship was supported. The differentiation of challenge and hindrance stressors falls in line with the inverted U-shaped theory. Prior studies have shown a curvilinear relation between challenge-related job demand (e.g., job complexity, scope) and strain (Baer \& Oldham, 2006). Boswell and colleagues (2004) find that job demand challenges are related to task performance through experienced challenge. Employees' performance might be hampered when they feel over challenged. The pattern holds true for the relationship between challenging job demands and creative performance. Studies have suggested that working under high pressure of time and excessive workload hinders creativity (Zhou \& Shalley, 2003). Baer and Oldham (2006) find a curvilinear relationship between experienced time pressure and creativity. A meta-analysis conducted by Byron et al., (2010) also finds stress stimuli have an inverted U-shaped relationship with creative performance. Given that cognitive, emotional, and behavioral engagement are important processes underlying creativity (Drazin, Glynn, \& Kazanjian, 1999), moderate levels of challenging job demands are likely to be associated with task and creative performance. Thus, the present study examines the possibility that both high and low levels of challenging job demands restraint creativity, whereas intermediate levels enhance it, resulting in a curvilinear inverted U-shape function.

Hypothesis 1: There will be an inverted U-shaped relation between challenging job demands and employee task performance (H1a) and creative performance (H1b) such that task performance or creative performance is greatest at moderate (intermediate) levels of challenging job demands.

\section{The Moderating Effect of Learning Orientation}

The curvilinear relation can unpack the positive and potentially adverse effect of job demands, it is important to identify the boundary condition that influences such relationship. Learning goal orientation is commonly defined as the desire to learn and develop a new competence, to improve and to do one's best, and to achieve a higher level of ability and talent (Dweck, 1986). Learning goal orientation is related to 
actions intended to improve an individual's competence. Therefore, we aim to clarify this association, and examine learning goal orientation as potential moderators of the association considering the effect of challenging job demands on performance.

Individuals respond differently to challenging job. Some may view a particular task as challenging while others may consider the same job as hectic. The relationship between challenging job demands and performance depends on the presence of salient individual differences like learning goal orientation. Learning goal orientation is characterized as a relatively stable tendency toward taking an active and selfinitiated approach to learning activities (Seibert, Kraimer, \& Crant, 2001). It reflects the degree to which an employee attaches importance to developing new skills, enjoying learning, showing curiosity for new ways of solving problems, and preferring challenging tasks.

The job demand-resource model (Bakker \& Demerouti, 2007) provides a useful framework for explaining the moderating effect of learning orientation. Knowledge can be viewed as important personal resource. Tendency to learn is an important job resource to cope with job related stress (Karasek, 1979), that is, resource gain (enabling process through learning). Individuals with high learning orientation have a stronger propensity to be continuously on the lookout for new knowledge (WandeWalle, Brown, Cron, \& Slocum, 1999). The negative effects of job demands can be counteracted through the availability and activation of job resources. Job demand and job resource (learning orientation) yield interact effect on performance outcomes.

When learning orientation is high, employees are more likely to respond to the challenges encountered at workplace with an approaching behavioral tendency. This can be explained by cognitive and emotional perspectives. First, from a cognitive perspective, people high on learning orientation tend to have more resource to cope with challenges. Learning orientation represents a tendency to acquire new knowledge and skills to enhance one's capability to deal with growing challenge stressors before the stressors become too demanding (Seibert et al, 2001). Demerouti et al (2001) recognize job-related knowledge as a form of resources, which prevents burnout and disengagement. Employees are more likely to feel personally responsible and work overtime when they have relevant knowledge and skills to successfully compete the task (Parker, Williams, and Turner, 2006). The propensity to acquire new knowledge and subsequently integrate the acquired knowledge into the existing knowledge set could increase employees' ability to deal with problems and uncertain situations (LePine et al., 2005). Prior studies support that learning orientation leads to positive task performance, such as a higher grade point average (Button, Mathieu, \& Zajac, 1996), and improved problem solving (Butler, 1993). Meanwhile, learning orientation also provides cognitive resources for creativity. Job resource predicts extra-role performance through engagement. Research finds a connection between learning orientation and creative self-efficacy which can lead to increased creative performance (Tierney \& Farmer, 2011). Zhou and George (2001) found that learning behaviors, such as seeking or giving feedback, making changes or improvements, and obtaining or providing expertise, are central to engaging in creative performance.

Second, from an emotional perspective, individuals high on learning orientation are more likely to experience the joy of taking challenges. Before job challenges grow beyond one's cognitive and physical limits, individuals with high learning orientation tend to perceive the increasing challenges positively. They treat the challenges as opportunities for growth which can yield job satisfaction (Lepine, et al, 2005), and improved performance. Gong et al. (2009) found that employees with strong learning orientation are more likely to feel capable of engaging in creative tasks and eventually show more creativity at work. Learning oriented individuals are more willing to acquire new skills to enhance their competences and try different ways of solving problems. To the extent that meeting challenges involves positive emotions, these employees are likely to be motivated to solve problems and make work-related improvements.

When learning orientation is low, however, the motivational effect of challenging jobs tends to be greatly undermined because of insufficient control or resource to cope with the demands. Employees who are low in learning orientation usually fail to identify learning opportunities and to acquire knowledge. A lack of learning activities could reduce employees' competency at work. On one hand, they might fail to respond to challenging job demands as they lack the expertise and skill to meet the challenges they face. 
Given the lack of opportunity to develop skills and to enrich experiences, employees tend to undergo stress when facing challenges, which further hinders performance at workplace. Therefore, when facing increasing challenging job demands, employees with low learning orientation tend to withdrawal from work and will lack the motivation to finish tasks, let alone generate creative ideas. As a result, challenging job demands, despite their motivating nature, are less likely to be transferred into performance outcomes for employees with low learning orientation.

Hypothesis 2: Employee learning orientation moderates the inverted U-shaped relationships between challenging job demands and task performance (H2a) and creative performance (H2b), such that a curvilinear effect will occur for employees with high learning orientation, but not for those with low learning orientation.

\section{RESEARCH METHODS}

\section{Sample and Procedures}

Data were collected from a service firm in a major city in Southern China. HR staff served as the coordinator in helping the research team collect data in the firm. 250 subordinates participated in the survey. Following Podsakoff et al.'s (2003) recommendations, the independent and dependent variables were collected from supervisors and individual employees separately to reduce the same source bias. The subordinates reported their challenging job demands and learning goal orientation (Time 1). Two weeks later, we collected participants' task performance and creative performance from their direct supervisors (Time 2).

The questionnaires together with a cover letter were sent to the respondents, explaining the objective of the survey, assuring confidentiality and voluntary participation in the study. Completed questionnaires were collected directly by research team and survey coordinators. The supervisors rated the task and creative performance of their subordinates. A code was used to match supervisor and subordinate responses.

Of the 250 questionnaires distributed, 226 completed questionnaires were returned. Ten were excluded from data analysis because of missing data or unmatched supervisor responses, with a response rate of $90 \% .51 \%$ of respondents were male, and $85 \%$ was married. The average age of the respondents was 30.90 years $($ s.d. $=8.52)$. They attained an average of 15.26 years $($ s.d. $=1.74)$ of education and a mean organizational tenure of 4.81 years $($ s.d. $=4.57$ ).

\section{Measures}

The questionnaires were administered in Chinese. The original question items were in English. Brislin's (1980) standard translation and back-translation procedure was used to ensure equivalence of the measures in the Chinese and English language versions.

\section{Challenging Job Demands}

A 6-item scale developed by Cavanaugh et al. (2000) was used to measure challenging job demands. A sample item is "The number of projects and or assignments I have." The alpha reliability was .81 in the present study.

\section{Learning Goal Orientation}

Employees completed VandeWalle's (1997) 5-item measure of learning goal orientation. A sample item is, "I am willing to select a challenging work assignment that I can learn a lot from." The alpha reliability was .84 . 


\section{Task Performance or In-role Performance}

The 7-item scale developed by Williams and Anderson (1991) was adopted to measure task performance. A sample item is "The subordinate meets formal performance requirements of the job." The scale's alpha reliability was .79 .

\section{Creative Performance}

Supervisors evaluated subordinates' creative performance using Zhou and George's (2001) 13-item creativity scale. One sample item is "This subordinate often has new and innovative ideas." The scale's alpha reliability was .95 .

\section{Control Variables}

Prior research by Zhang and Bartol (2010) found gender, age, education and tenure with supervisor to be significantly related to creativity. These demographic variables were employed as controls. Gender was coded 0 for Male and 1 for Female.

\section{Data Analysis}

Because individual respondents were nested within groups (under the same supervisor within a group), we followed the procedure recommended by Lam, Huang, and Snape (2007) and De Stobbeleir, Ashford, and Buyens (2011) and conducted two series of analyses. First, the model was tested using multilevel modeling (HLM 7.0) to control for the effects of different supervisors. Second, the moderated curvilinear relationship was tested using hierarchical regression analysis. Only the results of hierarchical regression analysis were reported here for two reasons. Hierarchical regression analysis yielded results close to those of the HLM analyses. In addition, HLM analysis fails to bootstrap samples and offer the simple slope test.

\section{RESULTS}

The descriptive statistics and correlations are given in Table 1.

TABLE 1

DESCRIPTIVE STATISTICS AND ZERO-ORDER CORRELATIONS IN THE STUDY

\begin{tabular}{|c|c|c|c|c|c|c|c|c|c|c|}
\hline Variables & $\mathrm{M}$ & SD & 1 & 2 & 3 & 4 & 5 & 6 & 7 & 8 \\
\hline 1. Gender & $51 \% \mathrm{n}$ & nale & - & & & & & & & \\
\hline 2. Age & 30.90 & 8.52 & $-.24 * *$ & & & & & & & \\
\hline 3. Education & 15.26 & 1.73 & -.04 & $-.26 * *$ & & & & & & \\
\hline 4. Tenure & 4.81 & 4.57 & -.07 & $.56^{* *}$ & $-.14 *$ & & & & & \\
\hline 5. Challenging job demands & 3.65 & 0.71 & -.12 & -.06 & -.01 & $-.18 * *$ & & & & \\
\hline 6. Learning orientation & 3.95 & 0.71 & -.04 & -.10 & .08 & -.10 & $.34 * *$ & & & \\
\hline 7. Task performance & 4.26 & 0.52 & -.10 & $.24 * *$ & .09 & .02 & .07 & .02 & & \\
\hline 8. Creative performance & 3.43 & 0.80 & $-.15^{*}$ & $.21 * *$ & .13 & $.23 * *$ & .10 & .09 & $.49^{* *}$ & - \\
\hline
\end{tabular}

$N=216$

$* p<.05, * * p<.01$

The moderated quadratic effects were examined with six steps. First, control variables were entered (step 1), followed by linear effect of challenging job demands (step 2). To assess challenging job demands curvilinearity, a quadratic challenging job demands term was introduced in Step 3. The moderator learning orientation and the interaction between challenging job demands and learning orientation were added to the model in Step 4 and 5 respectively. To evaluate the influence of learning orientation on this curve, the final model included learning orientation and its interaction with the challenging job demands 
quadratic (Step 6) while retaining all previous terms in the model. On the basis of substantive meaningfulness (Aguinis, 2004), retaining these product terms as covariates allowed us to substantiate curvilinearity in the final model (Ganzach, 1997).

Table 2 depicts the result for the outcomes of task performance and creative performance. In Step 3, there was no significant, negative quadratic relationship between challenging job demands and task performance $(\mathrm{b}=-.04$, s.e. $=.05, \mathrm{~ns})$ and creative performance $(\mathrm{b}=-.09$, s.e. $=.08, n s$.$) . Therefore$ Hypothesis 1a and $1 \mathrm{~b}$ were not supported. As can be seen in Step 6, learning orientation significantly interacted with the challenging job demands curve for task performance $\left(\mathrm{b}=-.16\right.$, s.e. $=.07, p<.05 ; \Delta \mathrm{R}^{2}$ $=.02, p<.05)$ and creative performance $\left(\mathrm{b}=-.25\right.$, s.e. $\left.=.10, p<.05 ; \Delta \mathrm{R}^{2}=.02, p<.05\right)$, providing support for Hypothesis $2 \mathrm{a}$ and $2 \mathrm{~b}$.

Following Aiken and West (1993), we further tested the maximum points of curves for task performance and creative performance. When challenging job demands was 0.25 and 0.17 , the moderate levels of \pm 0.71 range, the curves for task performance and creative performance reached the summit. That is to say, when employee have high learning orientation, the two performance outcomes are greater at moderate (intermediate) levels of challenging job demands. The results provide further support for Hypothesis $2 \mathrm{a}$ and $2 \mathrm{~b}$.

TABLE 2

RESULTS OF HIERARCHICAL REGRESSION ANALYSES

\begin{tabular}{|c|c|c|c|c|c|c|}
\hline \multirow[b]{2}{*}{ Independent variables } & $b$ se (entry) & $b$ se (final) & $\Delta \mathbf{R}^{2}$ & $b$ se (entry) & $b$ se (final) & $\Delta \mathbf{R}^{2}$ \\
\hline & \multicolumn{2}{|c|}{ Task performance } & \multicolumn{4}{|c|}{ Creative performance } \\
\hline Step 1: gender & $-.01(.07)$ & $-.01(.07)$ & $.11 * * *$ & $-.16(.11)$ & $-.16(.11)$ & $.11 * * *$ \\
\hline age & $02 * * *(.01)$ & $02 * * *(.01)$ & & $.01(.01)$ & $.01(.01)$ & \\
\hline education & $.05 *(.02)$ & $.05 *(.02)$ & & $.09 * *(.03)$ & $.08 * *(.03)$ & \\
\hline tenure & $-.02 *(.01)$ & $-.02 *(.01)$ & & $.03 *(.01)$ & $.03 *(.01)$ & \\
\hline $\begin{array}{l}\text { Step 2: challenging job } \\
\text { demands }\end{array}$ & $.05(.05)$ & $.06(.06)$ & .01 & $.15^{*}(.07)$ & $.16(.09)$ & $.12 *$ \\
\hline Step 3: CJD ${ }^{2}$ & $-.04(.05)$ & $-.05(.06)$ & .00 & $-.09(.08)$ & $-.06 \quad(.08)$ & .01 \\
\hline $\begin{array}{l}\text { Step 4: learning } \\
\text { orientation }\end{array}$ & $.01(.05)$ & $.13(.07)$ & .00 & $.09(.08)$ & $.25^{*}(.10)$ & .01 \\
\hline Step 5: CJD * LO & $.12(.06)$ & $.03(.07)$ & .02 & $.03(.10)$ & $-.11(.11)$ & .00 \\
\hline Step 6: $\mathrm{CJD}^{2} *$ LO & $-.16^{*}(.07)$ & $-.16^{*}(.07)$ & $.02 *$ & $-.25 *(.10)$ & $-.25^{*}(.10)$ & $.02 *$ \\
\hline
\end{tabular}

$* p<.05, * * p<.01, * * * p<.001$

$\mathrm{CJD}=$ challenging job demands, $\mathrm{LO}=$ learning orientation 
Figure 1a and Figure 1b provide an illustration of how learning goal orientation moderates the curvilinear relationship between challenging job demands and task performance (Figure 1a) and between challenging job demands and creativity (Figure 1b). Consistent with our hypothesis, the inverted-U effect is most pronounced for individuals with strong learning orientation. In contrast, individuals with weak learning orientation remained constant at both low and high levels of challenging job demands. Results of the simple slopes analysis summarized in Table 3 showed that the slope for challenging job demands for individuals with strong learning orientation was significant for task performance $(\mathrm{b}=-.16$, s.e. $=.06, p$ $<.05)$ and for creativity $(\mathrm{b}=-.24$, s.e. $=.10, p<.05)$, suggesting that the inverted $\mathrm{U}$ - shaped relationship occurs for individuals with strong learning orientation. The slope for challenging job demands for individuals with weak learning orientation was insignificant for task performance $(b=.08$, s.e. $=.08$, ns), and for creativity $(b=.12$, s.e. $=.12$, ns. $)$, suggesting that individuals with weak learning orientation do not engage in task performance or creative performance at differing levels of challenging job demands. These results provide further support for Hypothesis $2 \mathrm{a}$ and $2 \mathrm{~b}$.

FIGURE 1a

MODERATING EFFECT OF LEARNING ORIENTATION ON THE CURVILINEAR EFFECT OF CHALLENGING JOB DEMANDS ON EMPLOYEE TASK PERFORMANCE

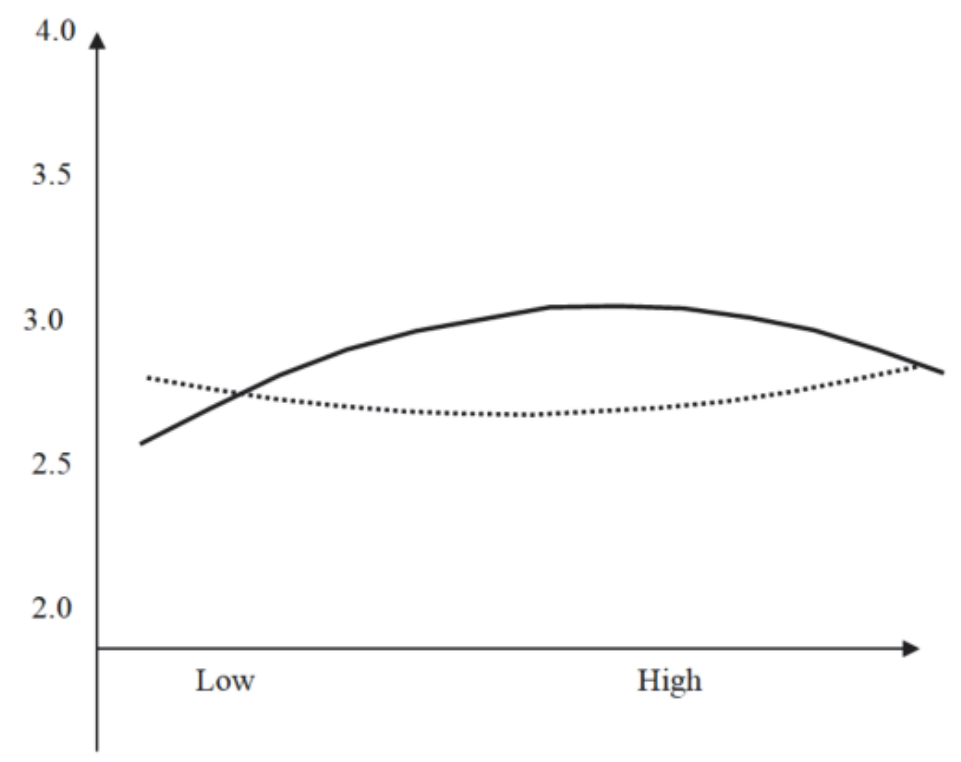

High learning orientation

Low learning orientation 
FIGURE 1b

MODERATING EFFECT OF LEARNING ORIENTATION ON THE CURVILINEAR EFFECT OF CHALLENGING JOB DEMANDS ON EMPLOYEE CREATIVE PERFORMANCE

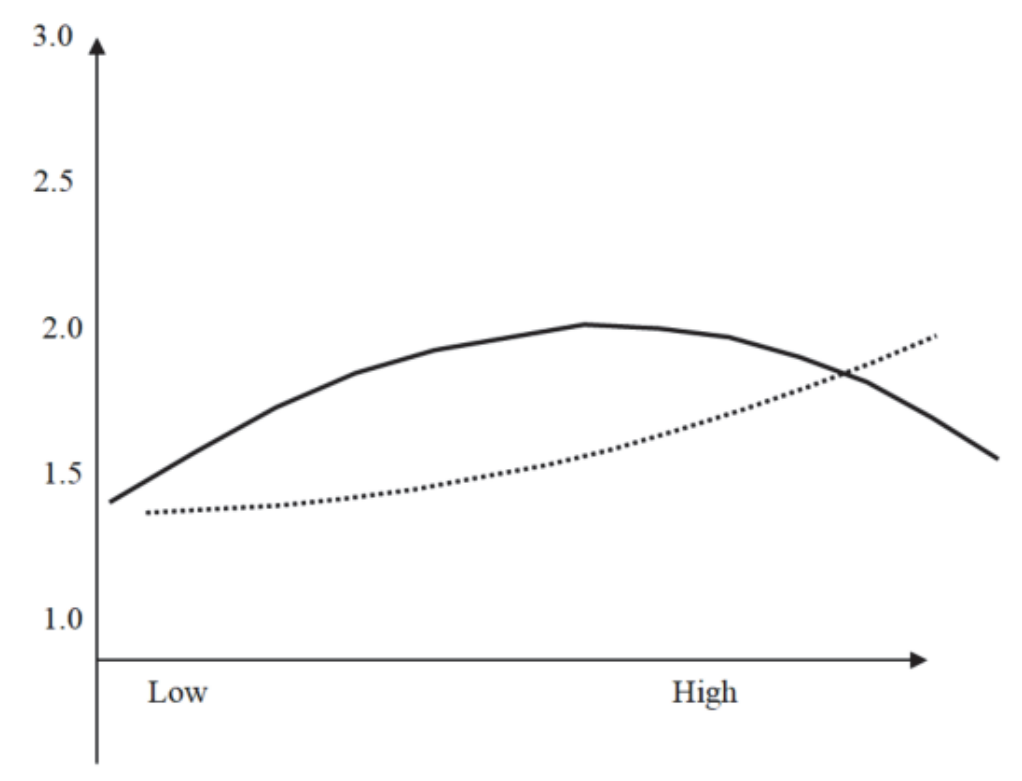

High learning orientation

Low learning orientation

TABLE 3

BOOTSTRAPPING RESULTS OF CURVILINEAR EFFECT AT VALUES OF MODERATORS

\begin{tabular}{llccccc}
\hline $\begin{array}{l}\text { Dependent } \\
\text { variables }\end{array}$ & $\begin{array}{l}\text { Moderator: } \\
\text { Leaning } \\
\text { orientation }\end{array}$ & Effect & SE & $\mathrm{t}$ & $p$ & $95 \%$ bias-corrected CI \\
\hline Task performance & Low & .07 & .08 & .83 & .41 & $(-.09, .23)$ \\
& High & -.16 & .06 & -2.52 & .01 & $(-.29,-.04)$ \\
$\begin{array}{l}\text { Creative } \\
\text { performance }\end{array}$ & Low & .12 & .12 & .94 & .35 & $(-.13, .36)$ \\
& High & -.24 & .10 & -2.49 & .01 & $(-.43,-.05)$ \\
\hline 10,000 bootstrapping samples & & & & &
\end{tabular}

\section{DISCUSSION}

In response to calls for more refined framework and consistent conclusions on the stressorperformance relationship (Gilboa et al., 2008), this paper makes several theoretical, empirical, and practical contributions. Theoretically, it enriches the stressor-performance model by including creativity as an outcome, in addition to task performance. Previous research separately studies the effect of challenge stressors on withdrawal behaviors, OCB, and task performance, without systematically incorporating these outcomes into the theoretical model. The paper addresses the inconsistent findings with regard to the relationship between job demands and performance outcome (LePine et al., 2005) by including both in-role (task performance), extra-role behaviors (creative performance), and the boundary condition into the job demand model to create a holistic view. 
This paper contributes to empirical evidence on job demands research by showing a moderated curvilinear relationship between challenging job demands and two different forms of performance. Previous research suggests that challenge-performance relationships might mainly depend on the range of challenge stressors experienced by individuals. However, the current study points out that the motivating effect of the challenging job demands might not work unless individuals have high learning orientation. Considering that the research shows that challenge stressors might influence individual task performance and creative performance through the same mechanism, it indicates that the job design-control model has explaining power on creative task performance and psychological wellbeing.

In this study, an inverted U-shaped relationship between challenging job demands and two types of performance was tested. Different from our initial assumption, individual performance does not correspond well with the changes of challenge stressors if learning orientation is out of the picture. The results show that the curvilinear relationships between challenging job demands and the two types of performance are only significant when individual learning orientation is considered. For individual with strong learning orientation, when challenging job demands grows from very low to medium level, employees are motivated to come up with more novel ideas beyond basic task requirements. This is because at this stage job becomes more interesting and intellectually challenging, and learning orientation facilitates employee proactivity by driving them to respond to environment challenges. As challenging job demand continues to grow, resulting in the tipping point where the positive effects of challenges and novelty start to wear off. When physical and intellectual challenges reach a level where an individual could no longer effectively cope with existing resources, both task performance and creativity will be compromised. Contrarily, for individuals with weak learning orientation, changes in the degree of challenging job demands do not significantly influence task performance or creative performance.

The above results add to the empirical evidence by suggesting that not all challenge stressor are "good", and people high on learning orientation might only respond to certain challenge stressors. Challenging job demand encompasses a variety of stressors, which have different motivating effects on performance. Some challenge stressors exert positive impact on performance while others might not. For example, Rodell and Judge (2009) find that challenging stressors can both cause anxiety and attentiveness. They suggest that some challenge stressors, such as job responsibility, might be more likely to cause attentiveness than anxiety, whereas other challenge stressors like time pressure relates more strongly with anxiety. As anxiety and attentiveness have different behavioral tendencies (Rodell \& Judge, 2009), they collectively generate an insignificant effect on performance across different levels. Similarly, according to job demand and resources model, job demand influences performance through energetic and motivational processes. Overtaxing aspects of challenging jobs can exhaust employee energy, while motivational process include dealing effectively with high challenge demands and prevents mental withdrawal or disengagement (Bakker \& Demerouti, 2007; Demerouti et al., 2001). Some challenge stressors, such as job responsibility, might bear more relevance with motivational processes and more likely to interact with learning orientation. When individuals have weak learning motivation, energetic process tends to prevail over motivational processes. Employees are likely to adopt an avoidance behavioral tendency even when challenge stressors are low.

Finally, this research contributes to practice in terms of job enrichment and job design. Meeting and exceeding customer and client expectations is not only important for service industry, but required in every job. An efficient and creative workforce is the key to organizations' success in market competitions. How to design a job properly is always a challenge for HR specialists across industries. The results of the study reveal that simply increasing job demands is not an answer to boosting task and creative performance. Although it is tempting to consider challenge stressors as "good," employers should carefully weigh the pros and cons of these stressors on task performance and creative performance. The current study suggests that job enrichment through adjusting challenging job demand in the workplace to boost performance should be implemented with caution. To develop a competitive workforce with high task proficiency and creativity, a fundamental issue might rest on changing employee learning orientation other than the job stressors. Following this path, HR specialists should put more emphasis on managing learning environments with respect to instructional design and administration. Job design is more 
meaningful if employees are willing to initiate learning activities to cope with difficulties and challenges. Otherwise, efforts on job enrichment and job design such as work-load reduction or flexible working hours might not induce favorable outcomes. This study also offers practical implication in conducting training and workshops on job demands, resources and ways to adjust and cope with job demands. At the same time, employees should focus on crafting their own jobs in order to stay engaged and perform well. Job crafting, according to Wrzesniewski and Dutton (2001), means that individuals actively construct their job, incorporating new tasks, simplifying, reducing or altering existing tasks based on their own preference. They shape the work environment such that their job demands and resources better fit their own needs and abilities. They can craft jobs in terms of adjusting job demands and acquiring more job resource, creating favorable conditions and opportunities for themselves in their work (Tims, Bakker, \& Derks, 2013).

\section{Limitations and Future Research Directions}

In the current study, we only examined the effect of challenging job demand on the performance as the initial effort to clarify the mixed findings. We did not include hindrance job demand in the model due to its established relationship with task performance and other key behavioral indicators. However, the two kinds of stressors always coexist in reality, and they would very likely interact with each other to influence individual behaviors. In addition, even though the challenging job demand scale developed by Cavanaugh et al. (2000) has been validated across different settings, the scale itself is not a comprehensive representation of all the various work experiences that could be challenging. The items are perhaps most representative of workload. Therefore, future studies are advised to further assess the interacting effects of the two kinds of stressors on performance, so as to facilitate better control mechanisms to avoid detrimental psychological outcomes such as burnout and depression. Along the similar line, researchers can explore the relationship between job demand and other proactive behaviors, such as helping behavior or voice behavior at workplace. While we believe that learning orientation serves a meaningful intervening mechanism to challenging job demand-creativity/performance relationship, there exist other personal coping strategies, such as goal orientation and self-monitoring, that deserves further examination. Future research could also include measures of both job demands and stress levels, investigating the process by which demands influence reported stress levels, why employees vary in their perceptions, and how these factors influence work outcomes.

\section{REFERENCES}

Aguinis, H. (2004). Regression analysis for categorical moderators. Guilford Press.

Aiken, L. S. \& West, S. G. (1993). Detecting interactions in multiple regression: Measurement error, power, and design considerations. The Score, 16 (1), 14-15.

Amabile, T. M. \& Gryskiewicz, N. D. (1989). The creative environment scales: Work environment inventory. Creativity Research Journal, 2, 231-252.

Baer, M. \& Oldham, G. R. (2006). The curvilinear relation between experienced creative time pressure and creativity: moderating effects of openness to experience and support for creativity. Journal of Applied Psychology, 91(4), 963.

Bakker, A. B., and Demerouti, E. (2007). The job demands-resources model: State of the art. Journal of Managerial Psychology, 22(3), 309-328.

Bakker, A. B. \& Demerouti, E. (2017). Job demands-resources theory: Taking stock and looking forward. Journal of Occupational Healthy Psychology, 22(3), 273-285.

Boswell, W. R., Olson-Buchanan, J. B., \& LePine, M. A. (2004). Relations between stress and work outcomes: The role of felt challenge, job control, and psychological strain. Journal of Vocational Behavior, 64(1), 165-181.

Brislin, R. W. (1980). Translation and content analysis of oral and written material, In H. C. Triandis and J. W. Berry (Eds.), Handbook of cross-cultural psychology: Methodology, Boston: Allyn and Bacon, 349-444. 
Butler, R. (1993). Effects of task-and ego-achievement goals on information-seeking during task engagement. Journal of Personality and Social Psychology, 65, 18-31.

Button, S., Mathieu, J., \& Zajac, D. (1996). Goal orientation in organizational behavior research: A conceptual and empirical foundation. Organizational Behavior and Human Decision Processes, 67, 26-48.

Byron, K., Khazanchi, S., \& Nazarian, D. (2010). The relationship between stressors and creativity: a meta-analysis examining competing theoretical models. Journal of Applied Psychology, 95(1), 201-212.

Cavanough, M.A., Boswell, W.R., Rochling, M.V., \& Boudreau, J.V. (2000). An empirical examination of self-reported work stress among U.S. managers. Journal of Applied Psychology, 85, 65-74.

De Stobbeleir, K. M., Ashford, S. J., \& Buyens, D. (2011). Self-regulation of creativity at work: The role of feedback-seeking behavior in creative performance. Academy of Management Journal, 54(4), 811-831.

Demerouti, E., Bakker, A. B., Nachreiner, F., \& Schaufeli, W. B. (2001). The job demands-resources model of burnout. Journal of Applied Psychology, 86(3), 499.

Drazin, R., Glynn, M. A., \& Kazanjian, R. K. (1999). Multilevel theorizing about creativity in organizations: A sense making perspective. Academy of Management Review, 24(2), 286-307.

Dweck, C. S. (1986). Motivational processes affecting learning. American Psychologist, 41, 1040-1048.

Dweck, C. (2007). Mindset: The new psychology of success. New York: Ballantine Books.

Dwyer, D. J. \& Ganster, D. C. (1991). The effects of job demands and control on employee attendance and satisfaction. Journal of Organizational Behavior, 12(7), 595-608.

Fredrickson, B. L. (2001). The role of positive emotions in positive psychology: The broaden-and-build theory of positive emotions. American Psychologist, 56, 218-226.

Ganzach, Y. (1997). Misleading interaction and curvilinear terms. Psychological Methods, 2(3), 235-247.

Gardner, D. G. (1990). Task complexity effects on non-task related movements: A test of activation theory. Organizational Behavior and Human Decision Processes, 45, 209-231.

Gilboa, S., Shirom, A., Fried, Y., \& Cooper, C. (2008). A meta-analysis of work demand stressors and job performance: examining main and moderating effects. Personnel Psychology, 61(2), 227-271.

Gong, Y., Huang, J. C., \& Farh, J. L. (2009). Employee learning orientation, transformational leadership, and employee creativity: The mediating role of employee creative self-efficacy. Academy of Management Journal, 52(4), 765-778.

Häusser, J. A., Mojzisch, A., Niesel, M., \& Schulz-Hardt, S. (2010). Ten years on: A review of recent research on the Job demand-control (-Support) model and psychological well-being. Work and Stress, 24(1), 1-35.

Hobfoll, S. E. (1989). Conservation of resources: A new attempt at conceptualizing stress. American Psychologist, 44(3), 513.

Janssen, O. (2001). Fairness perception as a moderator in the curvilinear relationship between job demands, and job performance and job satisfaction. Academy of Management Journal, 44(5), 1039-1050.

Karasek, R. A. (1979). Job demands, job decision latitude, and mental strain: Implications for job redesign. Administrative Science Quarterly, 24, 285-311.

Kelly, J. R., \& Karau, S. J. (1999). Group decision making: The effects of initial preferences and time pressure. Personality and Social Psychology Bulletin, 25, 1342-1354.

Lam, W., Huang, X., \& Snape, E. (2007). Feedback seeking behavior and leader-member exchange: Do supervisor attributions matter? Academy of Management Journal, 50, 348-363.

Lazarus, R. S. (1991). Emotion and adaptation, Oxford University Press.

LePine, J.A., Podsakoff, N.P., \& LePine, M.A. (2005). A meta-analytic test of the challenge stressorhindrance stressor framework: An explanation for inconsistent relationships among stressors and performance. Academy of Management Journal, 48, 764-775.

McCauley, C.D., \& McCall, M.W. (2014). Using experience to develop leadership talent: How organizations leverage on-the-job development. San Francisco: Jossey-Bass. 
Parker, S. K., Williams, H. M., \& Turner, N. (2006). Modeling the antecedents of proactive behavior at work. Journal of Applied Psychology, 91(3),636.

Perrewe, P. L. \& Ganster, D.C. (1989). The impact of job demands and behavioral control on experienced job stress. Journal of Organizational Behavior, 10, 213-229.

Podsakoff, N.P., LePine, J.A., \& LePine, M.A. (2007). Differential challenge stressor-hindrance stressor relationships with job attitudes, turnover intentions, turnover and withdrawal behavior: A metaanalysis. Journal of Applied Psychology, 92, 438-454.

Podsakoff, P. M., MacKenzie, S. B., Lee, J., \& Podsakoff, N.P. (2003). Common method biases in behavioral research: A critical review of the literature and recommended remedies. Journal of Applied Psychology, 88(5), 879-903.

Rodell, J. B. \& Judge, T. A. (2009). Can "good" stressors spark "bad" behaviors? The mediating role of emotions in links of challenge and hindrance stressors with citizenship and counterproductive behaviors. Journal of Applied Psychology, 94(6), 1438.

Roth, S. \& Cohen, L. J. (1986). Approach, avoidance, and coping with stress. American Psychologist, 41(7), 813

Schaufeli, W. B. \& Taris, T. W. (2005). The conceptualization and measurement of burnout: Common ground and worlds apart. Work and Stress, 19(3), 256-262.

Scheck, C. L., Kinicki, A. J., \& Davy, J. A. (1995). A longitudinal study of a multivariate model of the stress process using structural equations modeling. Human Relations, 48, 1481-1510.

Seibert, S. E., Kraimer, M. L., \& Crant, J. M. (2001). What do proactive do? A longitudinal model linking proactive personality and career success. Personnel Psychology, 54, 854-874.

Shalley, C, E., Gilson, L. L, \& Blum, T. C. (2000). Matching creativity requirements and work environment: Effects on satisfaction and intentions to leave. Academy of Management Journal, 43, 215-223.

Staw, B. M. \& Barsade, S. G. (1993). Affect and managerial performance: A test of the sadder-but-wiser vs. happier-and-smarter hypotheses. Administrative Science Quarterly, 38(2), 304-331.

Tierney, P. \& Farmer, S. M. (2011). Creative self-efficacy development and creative performance over time. Journal of Applied Psychology, 96(2), 277-293.

Tims, M., Bakker A.B., \& Derks, D. (2013). The impact of job crafting on job demands, job resources and well-being. Journal of Occupational Health Psychology, 18(2), 230-240.

Van der Doef, M., \& Maes, S. (1999). The job demand-control (-support) model and psychological wellbeing: a review of 20 years of empirical research. Work and Stress, 13(2), 87-114.

WandeWalle, D. (1997). Development and validation of a work domain goal orientation instrument. Educational and Psychological Measurement, 57(6), 995-1015.

WandeWalle, D., Brown, S. P., Cron, W. L., \& Slocum, J. W. (1999). The influence of goal orientation and self-regulation tactics on sales performance: A longitudinal field test. Journal of Applied Psychology, 84(2), 249-250.

Williams, L.J. \& Anderson, S.E. (1991). Job satisfaction and organizational commitment as predictors of organizational citizenship and in-role behaviors. Journal of Management, 17(3), 601-617.

Wrzesniewski, A. \& Dutton J. E. (2001). Crafting a job: Revisioning employees as active crafters of their work. Academy of Management Review, 26(2), 179-201.

Zhang X. \& Bartol, K.M. (2010). Linking empowering leadership and employee creativity: the influence of psychological empowerment, intrinsic motivation, and creative process engagement. Academy of Management Journal, 53, 107-28.

Zhou, J. \& George, J. M. (2001). When job dissatisfaction leads to creativity: Encouraging the expression of voice. Academy of Management Journal, 44, 682-696.

Zhou, J. \& Shalley, C. E. (2003). Research on employee creativity: A critical review and directions for future research. In J. Martocchio, (Ed). Research in Personnel and Human Resource Management, Elsevier, Oxford, UK, 165-217. 